\title{
EVALUASI DAN REHABILITASI STRUKTUR BANGUNAN YANG TELAH BERDIRI
}

\section{Dian Hastari Agustina}

\section{Dosen Tetap Prodi Teknik Sipil Universitas Riau Kepulauan Batam}

Abstrak

Kegagalan konstruksi bangunan dapat saja terjadi. Ada berbagai faktor yang penyebab. mungkin di dalam perencanaan sudah dilakukan dengan sangat teliti tetapi di dalam pelaksanaan tidak sesuai dengan perencanaan, atau sebaliknya karena perencanaan yang salah, tidak sesuai dengan standar perencanaan yang ada.

Evaluasi kekuatan didasarkan pada analisis, suatu penelitian lapangan yang menyeluruh dan akurat harus dikerjakan untuk mendapatkan dimensi dan detail dari komponen struktur, sifat dari material, dan kondisi lain yang berkaitan dengan struktur yang sesungguhnya dibangun. Dari kajian ini dapat ditetapkan langkah-langkah yang perlu ditempuh, misalnya perbaikan sebagian atau seluruh bangunan, agar struktur masih memenuhi persyaratan.

Kata kunci : Kegagalan konstruksi, evaluasi, rehabilitasi

\section{Pendahuluan}

Mungkin kita pernah menemukan, suatu bangunan yang baru selesai didirikan atau bangunan yang sudah beberapa tahun digunakan dilakukan pengujian (uji konstruksi). Lalu seberapa pentingkah uji konstruksi itu untuk dilaksanakan dan kriteria apa yang diperlukan untuk pekerjaan tersebut. Apabila timbul suatu keraguan mengenai keamanan dari suatu struktur atau komponen struktur (bangunan yang sudah lama digunakan ataupun bangunan yang baru berdiri), maka pejabat bangunan yang berwenang boleh meminta suatu penelitian terhadap kekuatan struktur dengan cara uji beban, atau cara 
analisis ataupun dengan kombinasi dari analisis dan uji beban (Tata Cara perencanaan struktur beton untuk bangunan gedung) .

\section{Uji Beban}

Bila penentuan evaluasi kekuatan didasarkan pada uji beban, seorang tenaga ahli yang mampu dan disetujui oleh pejabat bangunan yang berwenang harus selalu mengontrol pelaksanaan uji beban tersebut, suatu uji beban tidak boleh dikerjakan hingga bagian dari struktur yang akan dibebani telah mencapai usia minimum 56 hari. Bila pemilik bangunan dan semua pihak yang terlibat menyetujui maka boleh dilaksanakan pada umur lebih awal. Empat puluh delapan jam sebelum pelaksanaan uji beban, suatu beban yang

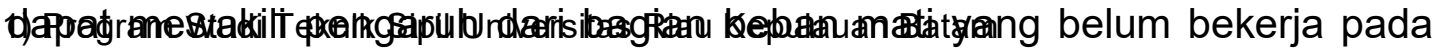
bagian tersebut harus dikerjakan dan tetap dikerjakan hingga semua pelaksanaan uji beban selesai.

Pengujian Pembebanan (Loading Test) struktur atau komponen struktur yang bertujuan untuk mengetahui lebih yakin, apakah struktur betul-betul mampu mendukung beban rencana atau tidak. Pengujian pembebanan dapat bersifat merusak, apabila setelah pembebanan telah dicapai lendutan yang bersifat permanen. Pengujian pembebanan untuk komponen struktur gedung yang terbuat dari beton bertulang diatur pada Peraturan Perencanaan Struktur Beton Bertulang untuk Gedung Tahun 2002

\section{Penelitian Analitis}

Dalam evaluasi kekuatan didasarkan pada analisis, suatu penelitian lapangan yang menyeluruh dan akurat harus dikerjakan untuk mendapatkan dimensi dan detail dari komponen struktur, sifat dari material, dan kondisi lain yang berkaitan dari struktur yang sesungguhnya dibangun. Analisis harus meyakinkan pejabat bangunan yang berwenang bahwa faktor beban telah memenuhi ketentuan dan tujuan yang ditentukan. Setelah diperoleh data tentang sistem dan dimensi struktur dan komponennya, hasil pengujian mutu material, pembebanan serta informasi lain yang terkait, dalam rangka evaluasi 
dilakukan analisis struktur, dengan masukan data yang telah diperoleh serta memperhatikan batasan peraturan/standar. Dari analisis struktur dihasilkan besaran mekanika yang digunakan untuk mengkaji, apakah masing-masing komponen struktur masih cukup baik, perlu perbaikan atau perkuatan atau harus dibongkar untuk diganti baru. Struktur atau komponen struktur dikatakan masih memenuhi persyaratan kekuatan, jika kuat rencana struktur masih lebih besar atau minimal sama dengan kuat perlu, yang dihitung berdasarkan beban-beban rencana yang akan bekerja (mati,hidup,angin,gempa,beban khusus dII). Persyaratan untuk evaluasi tersebut sama dengan persyaratan untuk perencanaan. Dalam perencanaan, baik beban maupun mutu bahan masih diatas kertas, berupa rencana, masih banyak faktor ketidakpastian. Sedangkan dalam evaluasi struktur existing data tentang dimensi aktual, tulangan aktual (Pada struktur beton), beban mati dan beban hidup masingmasing bagian, maupun mutu material hasil pengujian laboratorium dan lapangan telah diketahui secara pasti. Dengan diketahui data yang lebih pasti, dapat dilakukan penyesuaian faktor beban $\gamma$, maupun faktor reduksi kekuatan $\phi$ yang akan diberlakukan.

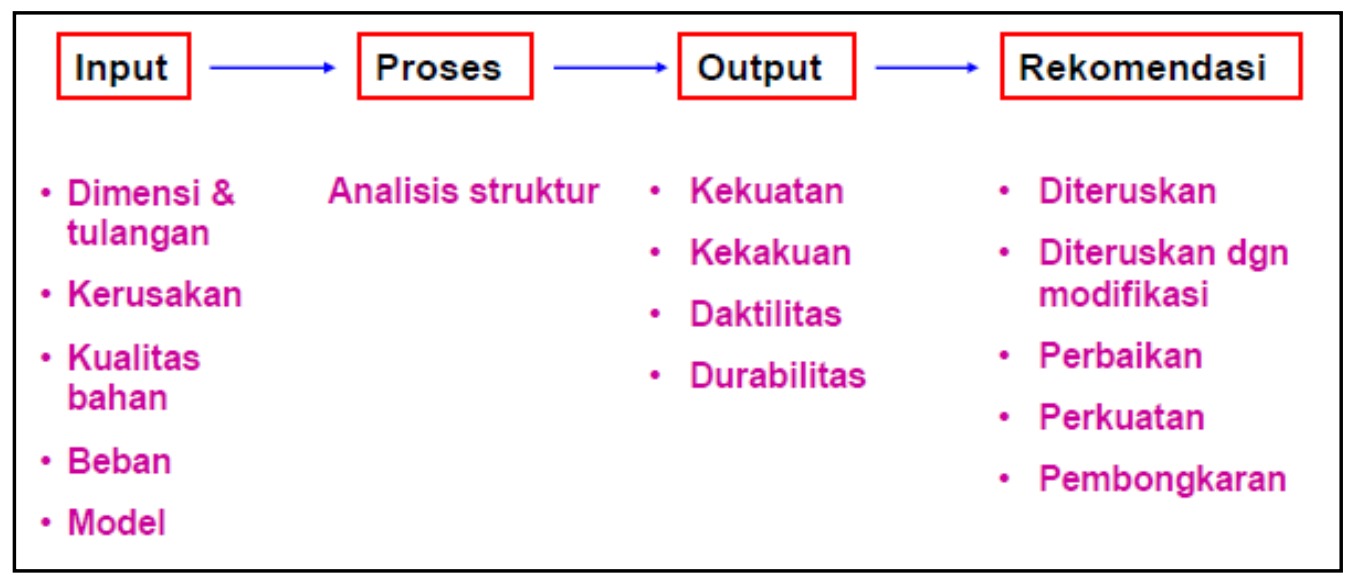

Gambar 1. Evaluasi Keamanan Struktur Bangunan (Cara Analitis) (Sumber : Triwiyono 2010)

\section{Penilaian Kinerja Struktur Bangunan Gedung}


Penilaian kinerja struktur bangunan gedung bertujuan untuk mendapatkan informasi yang mendalam mengenai kondisi existing struktur secara keseluruhan sebelum dilakukan tindakan rehabilitasi. Termasuk dalam kegiatan ini antara lain mengidentifikasi berbagai faktor yang mempengaruhi integritas dan kinerja struktur, misalnya jenis, penyebab dan tingkat kerusakan serta akibat yang ditimbulkan.

Prosedur penilaian biasanya diawali dengan on site Inspection secara visual di lapangan, pengukuran dimensi yang diikuti oleh kegiatan pengujian material baik di lapangan maupun di laboratorium. Selanjutnya dari hasil pengukuran dimensi, kondisi kerusakan dan hasil pengujian material dapat dilakukan evaluasi struktur. Dalam evaluasi kemampuan struktur dibandingkan dengan persyaratan yang tertuang dalam peraturan atau standar yang berlaku untuk mengetahui tingkat kinerja setiap bagian struktur atau secara keseluruhan. Dari kajian ini dapat ditetapkan langkah-langkah yang perlu ditempuh, misalnya perbaikan sebagian atau seluruh bangunan, agar struktur masih memenuhi persyaratan.

Beberapa contoh kerusakan struktur dapat dilihat pada gambar berikut ini.

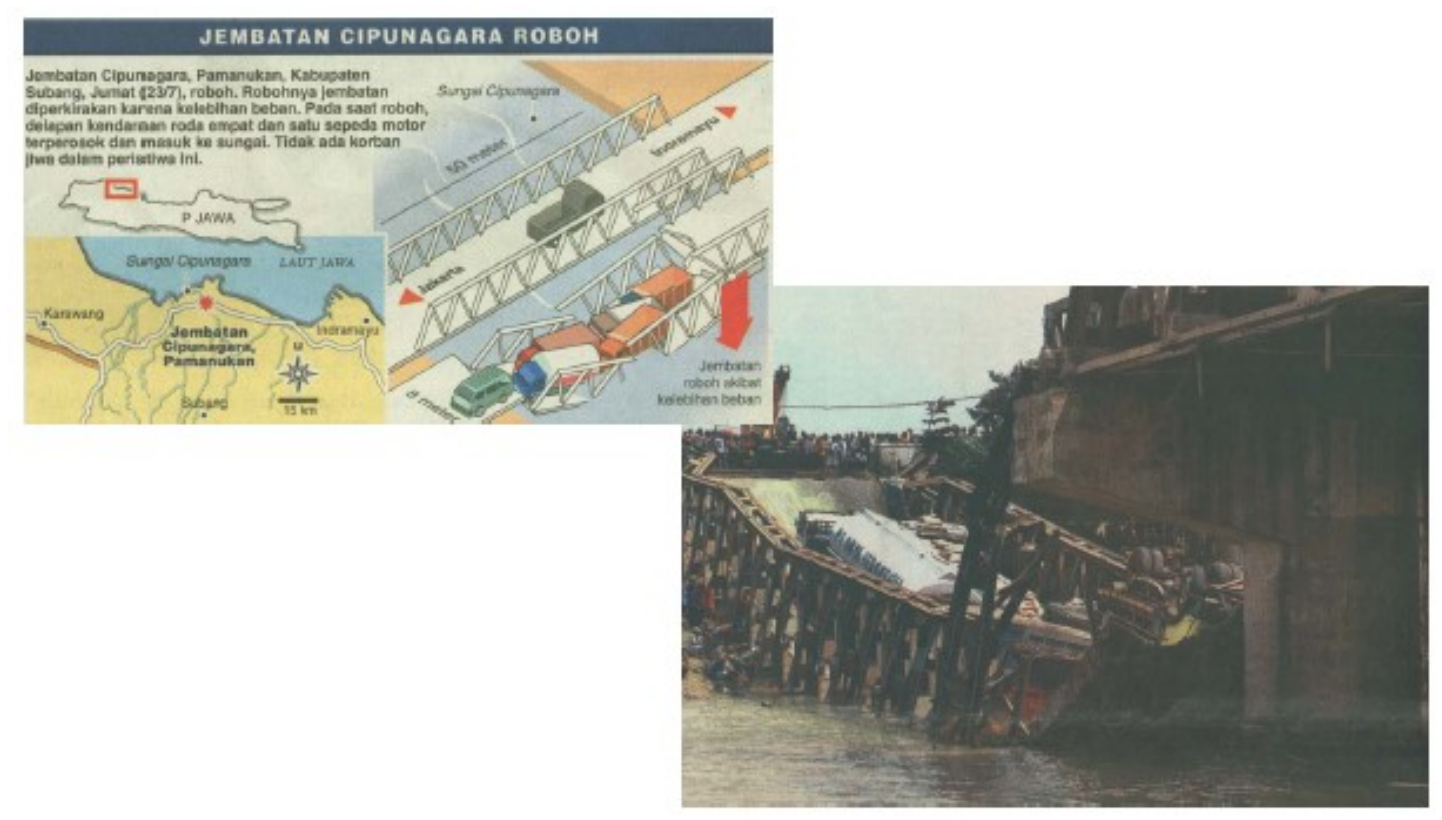

Gambar 2. Kerusakan jembatan akibat beban berlebih (overloading) 

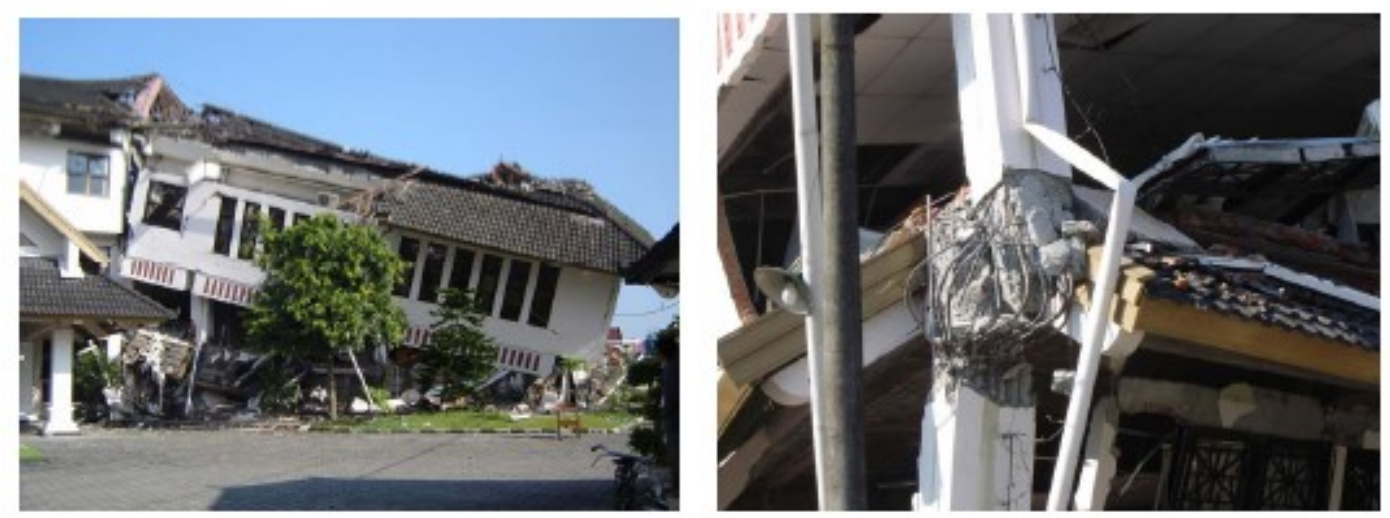

Gambar 3. Kerusakan gedung akibat beban gempa

\section{Perbaikan dan Perkuatan Struktur}

Pada umumnya ,semua bangunan sipil (gedung, jembatan, bangunan air) dirancang untuk sesuai dengan fungsi/ tujuan dengan mengindahkan persyaratan-persyaratan kekuatan, kekakuan, kestabilan, daktalitas dan ketahanan terhadap kondisi lingkungan. Namun setelah bangunan berdiri, terjadi kerusakan yang berakibat persyaratan-persyaratan tersebut tidak terpenuhi lagi. Kerusakan dapat terjadi sejak awal bangunan beroperasi yang disebabkan oleh perencanaan, pengerjaan dan pengawasan yang kurang baik, maupun setelah bangunan beroperasi yang disebabkan antara lain karena serangan secara fisik,kimia, Overloading, penurunan pondasi, gempa, kebakaran, fatique, kejatuhan pesawat terbang dll. Secara langsung maupun tidak, kerusakan akan meyebabkan degradasi kekuatan yang mempengaruhi kinerja struktur secara keseluruhan. Jika bangunan tidak segera ditangani perbaikan atau perkuatannya, kerusakan dapat berlanjut lebih parah lagi. Agar bangunan yang sudah rusak dapat terus difungsikan, diperlukan tindakan rehabilitasi yang dapat berupa perbaikan (retrofit) atau perkuatan (Strenghening).

Sebelum dilaksanakan tindakan rehabilitasi bangunan existing, diperlukan pemeriksaan, investigasi dan evaluasi kerusakan struktur utama maupun pendukung untuk mengetahui sejauh mana kelaikan bangunan. Dari 
hasil investigasi dan evaluasi dapat ditentukan metode perbaikan atau perkuatan yang paling optimal. Yang telah memasukkan beberapa kajian antara lain pendanaan/biaya, durasi pelaksanaan, ketersediaan bahan, alat, tenaga dll. Investigasi semacam ini sering disebut Rekayasa Forensik (Forensic Engineering). Prosedur rehabilitasi struktur dapat dilihat pada gambar 4.

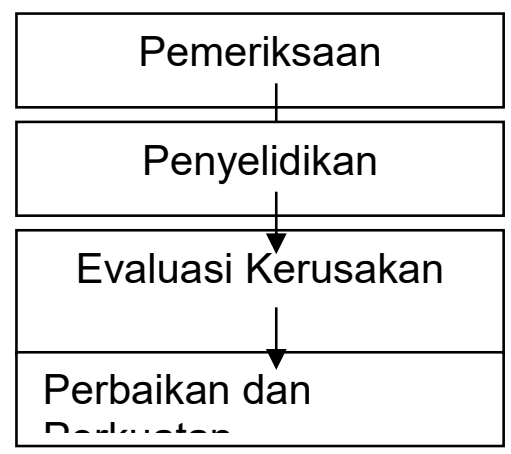

Gambar 4. Prosedur Umum Rehabilitasi Struktur (Sumber : Triwiyono 2003)

Secara umum semua bangunan pasca konstruksi cepat atau lambat akan mengalami kerusakan. Pada gambar 5 diperlihatkan biaya bangunan termasuk investasi awal, biaya pemeliharaan dan perbaikan/ perkuatan agar bangunan tetap dapat berfungsi sebagaimana mestinya. Semakin lama waktu penanganan perbaikannya, semakin tinggi biaya yang dibutuhkan. Dengan waktu penanganan perbaikan yang tepat akan didapatkan keuntungan secara ekonomi.

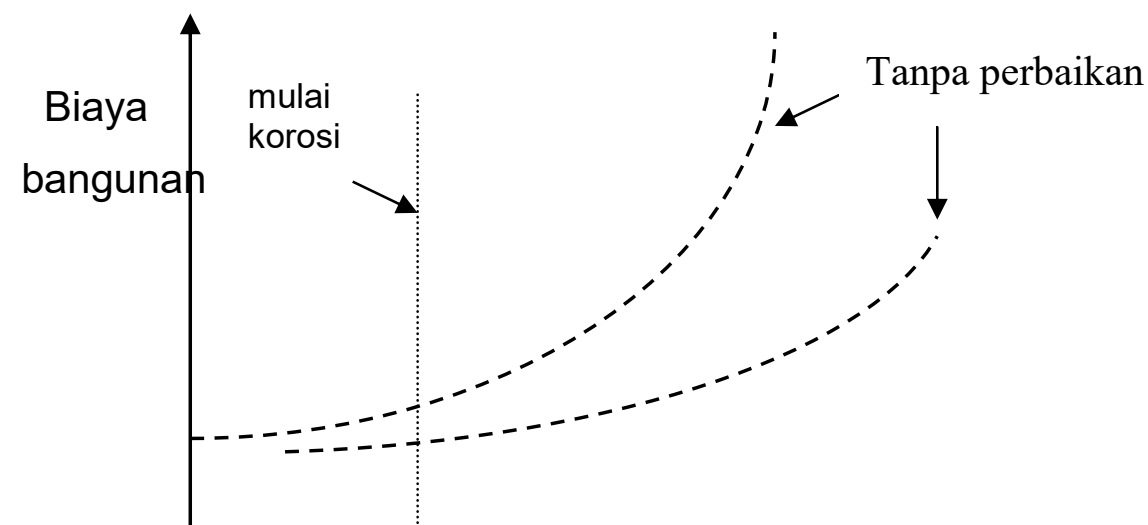



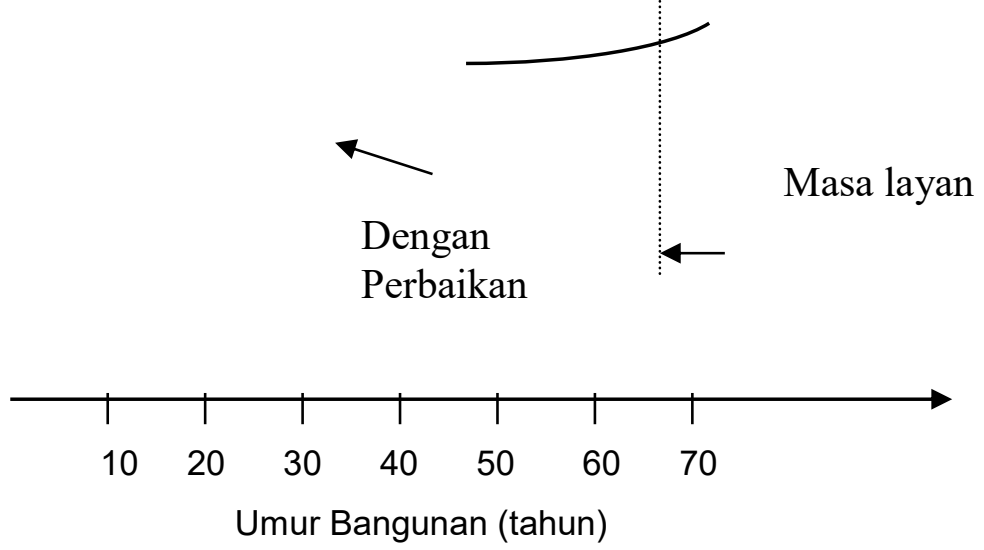

Gambar 5. Hubungan antara waktu dan biaya bangunan

( Sumber : Triwiyono,2003)

Perbaikan atau perkuatan struktur atau elemen-elemen struktur diperlukan apabila terjadi kerusakan yang menyebabkan degradasi yang berakibat tidak terpenuhi lagi persyaratan-persyaratan yang bersifat teknik yaitu Kekuatan, kekakuan, stabilitas, daktalitas dan ketahanan terhadap kondisi lingkungan (durability). Tidak terpenuhinya persyaratan-persyratan tersebut tidak hanya disebabkan karena kerusakan saja. Perubahan code dengan persyaratan yang lebih ketat, mungkin saja struktur yang sebelumnya dianggap laik pakai, menjadi tidak lagi sehingga diperlukan tindakan perkuatan.

Sebelum perbaikan/perkuatan dilaksanakan perlu dikaji terlebih dahulu terhadap aspek jenis dan penyebab kerusakan, tingkat kerusakan, biaya, ketersediaan material, alat, tenaga dan waktu pelaksanaan serta estetika dan arsitektur. Keputusan untuk melakukan perbaikan merupakan hasil kompromi kajian tersebut. Disamping itu masih perlu dipertimbangkan, apakah perbaikan juga akan mengantisipasi adanya resiko yang akan 
datang misalnya terjadinya gempa, kebakaran yang berulang atau memenuhi kriteria perencanaan yang terbaru. Idealnya perbaikan harus memenuhi kriteria perencanaan terbaru yang dapat lebih ketat dari perencanaan sebelumnya, namun seringkali berakibat biaya perbaikan yang sangat mahal. Rekomendasi perbaikan dan perkuatan perlu disertai dengan metode dan urutan pelaksanaannya antara bagian satu dengan bagian lainnya. Pelaksanaan perbaikan dan perkuatan tentunya jangan menimbulkan kerusakan atau keruntuhan sebagian atau struktur secara keseluruhan, yang dapat membahayakan jiwa pelaksana di lapangan. Evaluasi kinerja struktur perlu dilakukan pada kondisi struktur sedang dalam masa pelaksanaan perbaikan/perkuatan, agar diketahui dengan pasti bahwa cara dan urutan perbaikan yang telah disarankan aman untuk diterapkan di lapangan.

\section{Kesimpulan}

Evaluasi kinerja struktur bangunan menjadi sangat penting untuk mengetahui kelaikan suatu bangunan. Adalah baik jika evaluasi dilakukan secara berkala sehingga jika terjadi masalah pada struktur dapat secara cepat dan tepat diatasi. Dari sisi ekonomi juga akan lebih menguntungkan, karena jika masalah yang terjadi pada struktur tidak langsung ditangani, kerusakan akan semakin parah dan semakin tinggi biaya yang dibutuhkan untuk perbaikan.

\section{Daftar Pustaka}

Djoyowirono, S.,2004 "Manajemen Konstruksi", Biro Penerbit FT.UGM, Yogyakarta. Majalah Konstruksi.,Edisi April 2006, Elekmedia Komputindo, Jakarta.

Triwiyono,A.,2002, "Retrofitting dan Rehabilitasi Bangunan Gedung Magister Sarana dan Prasarana", FT.UGM, Yogyakarta. 
